\title{
A Novel Intervention for Management of Behavioral and Psychological Symptoms of Dementia in Nursing Home Communal Areas: Results of a Small-Scale Pilot Trial
}

\author{
Gloria Gutman $^{\mathrm{a}, \mathrm{b}, *}$, Avantika Vashisht ${ }^{\mathrm{c}}$, Taranjot Kaur ${ }^{\mathrm{d}}$, Mojgan Karbakhsh ${ }^{\mathrm{a}}$, Ryan Churchill ${ }^{\mathrm{b}}$ \\ and Amir Moztarzadeh ${ }^{\mathrm{a}}$ \\ ${ }^{a}$ Gerontology Research Centre, Simon Fraser University, Vancouver, BC, Canada \\ ${ }^{\mathrm{b}}$ Department of Gerontology, Simon Fraser University, Vancouver, BC, Canada \\ ${ }^{\mathrm{c} B i o m e d i c a l}$ Physiology and Kinesiology Department, Simon Fraser University, Vancouver, BC, Canada \\ ${ }^{\mathrm{d} B i o l o g y}$ Department, Simon Fraser University, Vancouver, BC, Canada
}

Received 25 October 2021

Accepted 1 November 2021

Pre-press 27 November 2021

Published 9 December 2021

\begin{abstract}
.
Background: Behavioral and psychological symptoms of dementia (BPSD) exhibited by persons with dementia (PwD) in nursing home communal areas are generally managed by segregation and/or pharmacological interventions.

Objective: This study trialed MindfulGarden (MG), a novel digital calming device, in a Canadian nursing home.

Methods: Participants were 15 PwD (mean age $=87.67$; 5m,10f; mean MMSE $=11.64 \pm 7.85$ ). Each was observed by a research assistant (RA) for an average of $8-10$ hours on two separate days. The RA followed them during time spent in communal areas of the nursing home including their unit's dining space, lounges, and corridors and spaces shared with other units (e.g., gym and gift shop) and documented any BPSD exhibited. Day-1 provided baseline data; on Day-2, residents were exposed to MG if nursing staff considered their BPSD were sufficiently intense or sustained to warrant intervention. Staff rated the impact as positive, neutral, or negative.

Results: On Day-1, 9 participants exhibited both aggressive and non-aggressive behaviors, 4 non-aggressive behaviors only, and 2 no BPSD. On Day-2, 7 exhibiting aggressive behaviors were exposed to MG. Staff reported MG as having distracting/calming effects and gave positive impact ratings to 6/13 exposures; there were no negative ratings. The most common aggressive BPSD on days of observation were pushing/shoving and screaming.

Conclusion: MG may have value as a "psychiatric crash cart" in de-escalating agitation and aggression in care home settings.

Keywords: Aggression, agitation, dementia, digital technology, feasibility studies, long-term care, nursing homes, pilot projects
\end{abstract}

\section{INTRODUCTION}

\footnotetext{
${ }^{*}$ Correspondence to: Gloria Gutman, PhD, Simon Fraser University Gerontology Research Centre, \#2800-515 West Hastings St. Vancouver, British Columbia V6B 5K3, Canada. Tel.:+1 604 263 5221; E-mail: gutman@sfu.ca.
}

Over half a million Canadians currently live with dementia, and the number is projected to double over the next ten years, making it one of the most common psychiatric disorders among the elderly residing in 
long term care facilities $[1,2]$. Behavioral and psychological symptoms of dementia (BPSD) include a wide variety of "non-cognitive" neuropsychiatric symptoms which almost universally present during the course of dementia. BPSD include agitation, aggression, apathy, depression, repetitive activities and questioning, psychosis, sleep problems, nighttime behaviors, and disinhibition [3]. These behaviors are associated with adverse outcomes, nursing home admission, and high levels of distress both in persons with dementia (PwD) and their caregivers [4]. These behaviors, especially when expressed as agitation and aggression, can pose risks to the safety of the PwD, other residents and staff when they occur in communal areas. More often than not, management consists of segregation, if encouragement and re-direction do not work [5]. Pharmacological interventions are also commonly employed. Given the undesirable side effects, there is a pressing need for non-pharmacological interventions that protect the safety and well-being of others while supporting the autonomy and dignity of the PwD who is acting out.

MindfulGarden (MG) is a novel digital device originally developed to de-escalate agitation in delirium patients in acute hospital settings [6]. It includes a mini-computer, TV screen (39" diagonal on a wheeled stand: height 54" from floor to top of screen), a high definition camera and a microphone to capture the viewer's vocalizations and movements. This input drives a garden display of layered calming motion pictures (blossoming flowers and butterflies) that increase in number and velocity in response to increased intensity of voice and motion.

In this pilot study, we aimed to determine the effect of MG on BPSD occurring in communal areas of a nursing home in British Columbia, Canada. This study is part of a larger feasibility trial conducted there in 2018-2020. Other parts of the study examined $\mathrm{MG}$ as a tool for calming residents during morning and evening personal care [7] and during bathing [8].

\section{METHODS}

\section{Participants}

Fifteen PwD (mean age: $87.67 \pm 7.26 ; 5 \mathrm{~m}, 10 \mathrm{f}$ ) screened by the facility's care staff for eligibility based on a diagnosis of dementia and exhibiting BPSD were included in the study. Of these, 5 were ambulatory, 3 used walkers, and 7 were wheelchair bound. The dementia type was Alzheimer's disease in 7, vascular dementia in 2, unspecified dementia in 2 , and not indicated in the case of 4 . Based on information in the residents' medical records at the facility, the mean Mini-Mental State Examination (MMSE) was $11.64 \pm 7.85$ and 11 were receiving anti-psychotic or anti-anxiety medications.

\section{Instrument}

A 26-item agitated behavior checklist, developed for a previous study [9] and based on the CohenMansfield Agitation Inventory [10] and the work of Gutman, MacFadgen, and Killam [11], was used to manually record BPSD. The checklist includes 4 categories of BPSD: non-aggressive physical, aggressive physical, non-aggressive verbal and aggressive verbal (see Table 1 for behaviors within each BPSD category).

\section{Procedures}

As indicated above, this study is part of a larger pilot trial examining the calming effect of MG conducted in 2018-2020 at a 212 bed long-term care home in British Columbia, Canada. After ethical approval (by the Simon Fraser University Research Ethics Board), $30 \mathrm{PwD}$ were eligible for inclusion, on the basis of previously exhibiting BPSD, of whom 25 were consented to participate by their Substitute Decision Maker. At the time this sub-study was conducted, 5 were deceased, consent had been withdrawn in the case of 3, 1 had been excluded due to severe visual impairment (could not see images on the screen), and 1 because he seldom left his room. The PI of the project met with the senior staff (RNs) and the heads of each of the 10 units (LPNs) that comprise the facility to describe the purpose and procedures of the study and trained the study research assistants (RAs).

Each PwD was observed by an RA on two separate days who followed them during time spent in communal areas of the nursing home [average 8-10 $\mathrm{h}$ of observation per PwD per day]. The communal areas where observation took place included the unit's dining space, lounges, corridors, multipurpose room, patio/outside area, and the gym, gift shop, hair salon, faith room, and other spaces shared by all units.

For each resident observed, the RA was instructed to fill out a form that included spaces to indicate the time of day that the observation began and ended, any of the 26 BPSD shown in Table 1 that the resident exhibited, the time of day that the behavior began and ended, the location where the behavior occurred, the 
Table 1

BPSD categories and behaviors

\begin{tabular}{lll}
\hline & Non-aggressive & Aggressive \\
\hline Physical & Restlessness & Biting \\
& Physical Resistance & Kicking \\
& Repetitive Mannerisms & Spitting \\
& Slapping \\
& Elbowing \\
& Scratching \\
& Pulling hair \\
& Throwing objects \\
& Pushing/shoving \\
& & Hitting/punching \\
& Pinching/squeezing \\
& Muttering & Threatening gesturing \\
\hline Derbal & Screaming \\
& Strange noises & Name calling \\
& Verbal resistance & Verbal threats \\
Repetitive words & Cursing, directed at staff \\
Complaining/negativism & Hostile, accusatory language \\
\hline
\end{tabular}

staff's response to the behavior, its impact on others if any, and the resident's response to the removal of MG if exposed to it.

Day-1 provided a baseline of number and type of BPSD exhibited. On Day-2, if the RA observed any of the verbal or physical aggressive behaviors shown in Table 1, they consulted with the senior nursing staff on duty who had observed the resident's behavior and interaction with MG. If the nurse agreed that intervention was required (based on their routine threshold for BPSD management), the RA wheeled MG to the communal area and placed it within two feet of the PwD, turned on the device and directed the PwD's attention to the screen. The screen remained active for 10-20 min, after which MG was removed by the RA. Subsequently, the RA asked the consulted nurse "how would you rate the impact of exposure to MG on the resident? Was it a) positive (BPSD de-escalated), b) negative (BPSD increased in number or intensity), or c) neutral (BPSD continued, no change occurred)? To describe and justify their rating, they were asked 'why do you say so?'.

\section{Data analysis}

SPSS version 22 was used for statistical analysis using descriptive statistics (mean and standard deviation).

\section{RESULTS}

The mean observation period on Day-1 was $8.71 \pm 3.93 \mathrm{~h}$. Within a total of $130.68 \mathrm{~h}$ of observation on Day-1, 2 PwD did not exhibit any BPSD, 4 exhibited non-aggressive BPSD only and 9 exhibited both aggressive and nonaggressive BPSD. Among the 13 PwD showing one or more BPSD, the first appeared after $2.27 \pm 1.97 \mathrm{~h}$ of observation. The most common BPSD on Day-1 were repetitive mannerism $(n=8)$, physical resistance and verbal resistance $(n=7$, each) and restlessness $(n=5)$. On Day-2, the mean observation time was $10.10 \pm 2.78 \mathrm{~h}$. Within $151.45 \mathrm{~h}$ of observation, $4 \mathrm{PwD}$ did not exhibit any BPSD, 3 exhibited non-aggressive BPSD only, and 8 exhibited both aggressive and nonaggressive BPSD; the first BPSD appeared after $2.50 \pm 2.85 \mathrm{~h}$ of observation. BPSD were considered sufficiently intense or sustained to warrant exposure to $\mathrm{MG}$ in the case of $7 \mathrm{PwD}$. As shown in Tables 2, 3 were exposed once (exposure rated as having neutral effect in each case), 2 were exposed twice (rated positive-positive; neutral-positive), and 2 were exposed 3 times (positive-positive-neutral; neutralneutral-positive). The main explanation for positive ratings by the staff was distraction. Following exposure, the removal of MG was not difficult; all residents had a neutral response to its removal.

Table 3 presents two examples of participants exposed to MG, showing the full period of observation and the RA's notes. Finally, it should be noted that over the two days of observation the most common aggressive BPSD were screaming and pushing/shoving.

\section{DISCUSSION}

This small-scale trial investigated the incidence and pattern of BPSD exhibited while PwD spent time 
Table 2

Participants exposed to MG ( $n=7)$ showing BPSD exhibited Day-2, number of exposures, and staff MG impact rating and explanation

\begin{tabular}{|c|c|c|c|c|c|}
\hline ID & BPSD & $\begin{array}{c}\text { Number of times } \\
\text { exposed to MG }\end{array}$ & $\begin{array}{l}\text { Location of } \\
\text { MG exposure }\end{array}$ & $\begin{array}{l}\text { Impact Rating } \\
\text { by the staff }\end{array}$ & Explanation by staff \\
\hline 2 & $\begin{array}{l}\text { RW, NC, CD, HA, SR, } \\
\text { CN, VT, PS, TG, TO }\end{array}$ & 1 & $\mathrm{TV}$ area & Neutral & $\begin{array}{l}\text { Behavior is the same as before MG } \\
\text { was introduced. When MG was } \\
\text { removed, resident showed no } \\
\text { reaction. }\end{array}$ \\
\hline 4 & $\begin{array}{l}\text { VR, RL, CN, PR, HA, } \\
\text { SL, TG, KC, NC }\end{array}$ & 2 & $\mathrm{TV}$ area $-\mathrm{TV}$ area & Positive-Positive & MG distracted the resident. \\
\hline 6 & $\mathrm{TO}, \mathrm{RL}, \mathrm{MU}$ & 1 & Dining area & Neutral & $\begin{array}{l}\text { The resident was indifferent when } \\
\text { MG was removed. }\end{array}$ \\
\hline 7 & $\mathrm{PR}, \mathrm{VR}, \mathrm{SR}, \mathrm{SN}, \mathrm{MU}$ & 3 & $\begin{array}{l}\text { Dining area- Dining area- Dining } \\
\text { area }\end{array}$ & Positive-Positive-Neutral & $\begin{array}{l}{\left[1^{\text {st }} \text { and } 2^{\text {nd }} \text { exposure to MG: }\right]} \\
\text { Distracted the resident. } \\
{\left[3^{\text {rd }} \text { exposure to MG]: Behavior still }\right.} \\
\text { continued. }\end{array}$ \\
\hline 9 & PR, RM, RL, PQ, PS, VR & 2 & $\begin{array}{l}\text { Dining area - Entrance area between } \\
\text { nursing station and kitchen }\end{array}$ & Neutral-Positive & $\begin{array}{l}\text { Resident was restless } \\
{\left[2^{\text {nd }} \text { exposure: The resident calmed }\right.} \\
\text { down; Not pacing. }\end{array}$ \\
\hline 10 & $\mathrm{RL}, \mathrm{SN}, \mathrm{SR}$ & 1 & Dining area & Neutral & $\begin{array}{l}\text { Hard to tell, this resident does not } \\
\text { communicate, they [BPSD] } \\
\text { escalate and deescalate quickly. }\end{array}$ \\
\hline 11 & RM, RL, CD, SR, MU & 3 & $\begin{array}{l}\text { Dining area -Dining area- Dining } \\
\text { area }\end{array}$ & Neutral-Neutral-Positive & $\begin{array}{l}{\left[1^{\text {st }} \text { and } 2^{\text {nd }} \text { exposure to MG:] It did }\right.} \\
\text { not make any difference. } \\
{\left[3^{\text {rd }} \text { exposure }\right] \text { : First no reaction, then }} \\
\text { distracted a little }\end{array}$ \\
\hline
\end{tabular}

PR, physical resistance; RM, repetitive mannerisms; RL, restlessness; VR, verbal resistance; RW, repetitive words; SN, strange noises; MU, muttering; DE, demanding; CN, complaining/negativism; PS, pushing/shoving; SL, slapping; HP, hitting/punching; PQ, pinching/squeezing; PH, pulling hair; SC, scratching; BT, biting; SP, spitting; EL, elbowing; KC, kicking; TG, threatening gestures; TO, throwing objects; NC, name calling; VT, verbal threats; CD, cursing at care staff; HA, hostile accusatory language; SR, screaming. 
Table 3

Two examples of Day2 observations

\begin{tabular}{|c|c|c|c|c|c|c|}
\hline ID\# & $\begin{array}{l}\text { Time BPSD } \\
\text { exhibited }\end{array}$ & Location & BPSD types & $\begin{array}{c}\text { MG } \\
\text { implemented? }\end{array}$ & Impact & RA notes \\
\hline \multirow[t]{6}{*}{4} & $11: 08-11: 10$ & gym & VR, RL, CN & - & - & - \\
\hline & $11: 12-11: 12$ & gym & $\mathrm{PR}$ & - & - & - \\
\hline & $16: 45-16: 45$ & dining area & HA & - & - & - \\
\hline & $17: 05: 17: 06$ & dining area & HA, VR & - & - & $\begin{array}{l}\text { The nurse said no to MG; "she would want her plate; try } \\
\text { MG after dinner" }\end{array}$ \\
\hline & $18: 19-18: 30$ & $\mathrm{TV}$ area & SL, KC, TG & Yes & Positive & $\begin{array}{l}\text { The resident got quite focused on MG, relaxed her down } \\
\text { quite quickly. }\end{array}$ \\
\hline & $19: 17-19: 29$ & $\mathrm{TV}$ area & $\mathrm{TG}, \mathrm{NC}$ & Yes & Positive & $\begin{array}{l}\text { The resident got into verbal fight with another resident } \\
\text { about being safe; other resident had accusing finger in } \\
\text { her face... MG was introduced, after a few minutes, } \\
\text { calmed down. }\end{array}$ \\
\hline \multirow[t]{8}{*}{7} & $8: 11-8: 12$ & dining area & VR & - & - & Staff gave different pills. \\
\hline & $8: 18-8: 18$ & dining area & SR & - & - & - \\
\hline & $8: 22-8: 34$ & dining area & SN, MU, SR & Yes & Positive & $\begin{array}{l}\text { The resident followed and counted butterflies, the nurse } \\
\text { thought that it calmed her. }\end{array}$ \\
\hline & $12: 20-12: 21$ & dining area & VR & - & - & The staff stopped her a while, then tried again. \\
\hline & $16: 25-16: 42$ & dining area & SR & Yes & Positive & $\begin{array}{l}\text { The resident following and counting butterflies, required } \\
\text { medication, intermittent crying whenever butterflies } \\
\text { disappeared. }\end{array}$ \\
\hline & $17: 26-17: 26$ & dining area & PR, VR & - & - & - \\
\hline & $17: 38-17: 38$ & dining area & SR & - & - & - \\
\hline & $18: 05-18: 16$ & dining area & SR & Yes & Neutral & $\begin{array}{l}\text { The resident kept repeating she wanted to go home, } \\
\text { calmed down a little. }\end{array}$ \\
\hline
\end{tabular}

PR, physical resistance; RM, repetitive mannerisms; RL, restlessness; VR, verbal resistance; RW, repetitive words; SN, strange noises; MU, muttering; DE, demanding; CN, complaining/negativism; PS, pushing/shoving; SL, slapping; HP, hitting/punching; PQ, pinching/squeezing; PH, pulling hair; SC, scratching; BT, biting; SP, spitting; EL, elbowing; KC, kicking; TG, threatening gestures; TO, throwing objects; NC, name calling; VT, verbal threats; $\mathrm{CD}$, cursing at care staff; HA, hostile accusatory language; SR, screaming. 
in communal areas of a nursing home and the calming effect of a novel digital technology. Most previous studies of BPSD in nursing homes have focused on resistance to care [12, 13]. BPSD exhibited in communal areas of a nursing home present different challenges. A systematic review of resident-resident aggression (RRA) showed that a history of aggressive behaviors is one of the main contributing factors and that RRA most commonly occur in communal spaces in nursing homes [14]. In our study, although eligibility to participate included a history of aggressive behavior, most participants were calm most of the time. The most common BPSD triggering intervention on Day-2 was screaming. A survey across 21 nursing homes in Australia showed that staff considered shouting, wandering and restlessness to have the highest importance considering incidence, frequency, and difficulty of management [15]. Another study showed that staff believed BPSD in one PwD can provoke agitation among others [16]. While our RAs did not report an increase in screaming on the part of other residents, an increase in agitation may well have occurred and should be systematically monitored in future studies.

Use of natural elements and positive images have shown some promising results in decreasing care refusals in PwD [12, 17]. As with the staff in our study, a recent study [18] indicated that Australian residential care staff believed "distraction" can be helpful in managing aggression in PwD. MG is a novel device providing both sensory stimulation and distraction. Working through primary stimuli (visual only in the case of the MG model we used) without relying on intellectual abilities or cognitive functions makes sensory stimulation an ideal approach for reaching persons with advanced dementia [19, 20]. The nature-like visualizations generated by MG share similarities with photographic sky compositions (e.g., SkyCeilings ${ }^{\mathrm{TM}}$ ) which have shown some positive results in preventing delirium among PwD in an emergency room setting [21]. One distinguishing difference between MG and other sensory stimulation interventions such as Snoezelen [22], is that MG uses the Unity game engine [23] to generate the underlying software algorithms that create the calming objects to distract PwD and alleviate BPSD.

Our study demonstrates that only an exposure of $10-20 \mathrm{~min}$ is required to redirect the resident's attention and have a calming effect. MG is easy to operate and does not require extensive training to do so. It also does not involve modifications to the built environment.
Our study had some limitations, including the decision to introduce MG when the RA and the nursing staff considered the behavior to be sufficiently challenging to warrant intervention. The intervention threshold was subjective, relying upon staff's self-definition of situations that, according to our instruction, would normally trigger segregation and/or medication administration in the home. We did not collect data on the training or years of practice of the nursing staff, all of whom were regular unionized employees of the nursing home. In this small pilot study, we also did not assess inter-rater reliability of impact assessment which was also subjective. More objective criteria/tools (e.g., changes in heart rate, blood pressure) can be implemented in future research to capture the calming effect of MG but this was beyond the scope of the present study.

\section{Conclusion}

Use of MG in this study was analogous to that of a "psychiatric crash cart" [24], replacing the usual practice of segregation and/or medication administration, when agitation or aggression occurs in communal areas of nursing homes with the introduction of a digital device. Logistical issues to be explored in future studies include whether it is more effective to take the device to the resident or the resident to MG and whether the addition of sound would increase its ability to capture and sustain the attention of PwD and serve as a distractor and calming influence.

\section{ACKNOWLEDGMENTS}

The authors have no acknowledgments to report.

\section{FUNDING}

This work was supported by the Good Samaritan Delta View Care Centre through a grant from the Centre for Aging and Brain Health Innovation (CABHI); and a grant from the AGE-WELL Network of Centres of Excellence.

\section{CONFLICT OF INTEREST}

Prior to the study, the first author (G.G) acted as an advisor for MindfulGarden but derived no financial or other tangible benefits from MindfulGarden Digital Health, Inc. or Switch United, the MindfulGarden developers. 


\section{REFERENCES}

[1] Chambers LW, Bancej C, McDowell I (2016) Prevalence and monetary costs of dementia in Canada: population health expert panel. Alzheimer Society of Canada in collaboration with the Public Health Agency of Canada, Toronto, Ontario, Canada.

[2] Seitz D, Purandare N, Conn D (2010) Prevalence of psychiatric disorders among older adults in long-term care homes: A systematic review. Int Psychogeriatr 22, 1025-1039.

[3] Kales HC, Gitlin LN, Lyketsos CG (2015) Assessment and management of behavioral and psychological symptoms of dementia. BMJ 350, h369.

[4] Toot S, Swinson T, Devine M, Challis D, Orrell M (2017) Causes of nursing home placement for older people with dementia: A systematic review and meta-analysis. Int Psychogeriatr 29, 195-208.

[5] Backhouse T, Penhale B, Gray R, Killett A (2018) Questionable practices despite good intentions: Coping with risk and impact from dementia-related behaviours in care homes. Ageing Soc 38, 1933-1958.

[6] MindfulGarden Digital Health, Inc. (2021) https:// mindfulgarden.com/, Last accessed September 27, 2021.

[7] Gutman G, Vashisht A, Kaur T, Churchil R, Moztarzadeh A, Karbakhsh M (2020) Feasibility study of a digital screenbased calming device for managing BPSD during care. Innov Aging 4 (Suppl 1), 755.

[8] Gutman G, Karbakhsh M, Vashisht A, Kaur T, Churchil R, Moztarzadeh A (2021) Feasibility study of a digital screenbased calming device (MindfulGarden) for bathing-related agitation among LTC residents with dementia. Gerontechnology 20, 1-8.

[9] Cooke H, Gutman G (2005) Improving the bathing experience for residents with dementia. Can Nurs Home 16, 13-15.

[10] Cohen-Mansfield J, Marx MS, Rosenthal AS (1989) A description of agitation in a nursing home. J Gerontol 44, M77-84.

[11] Gutman G, MacFadgen L, Killam J (1995) Psychogeriatric client identification project - Phase 1 Final Report. Continuing Care Division, Victoria, B.C. https://Summit.Sfu.ca/Item/539, Last Accessed August 13, 2021.

[12] Backhouse T, Dudzinski E, Killett A, Mioshi E (2020) Strategies and interventions to reduce or manage refusals in personal care in dementia: A systematic review. Int $J$ Nurs Stud 109, 103640.

[13] Konno R, Kang HS, Makimoto K (2014) A best-evidence review of intervention studies for minimizing resistance-tocare behaviours for older adults with dementia in nursing homes. J Adv Nurs 70, 2167-2180.
[14] Ferrah N, Murphy BJ, Ibrahim JE, Bugeja LC, Winbolt M, LoGiudice D, Flicker L, Ranson DL (2015) Resident-toresident physical aggression leading to injury in nursing homes: a systematic review. Age Ageing 44, 356-364.

[15] Koder D, Hunt GE, Davison T (2014) Staff's views on managing symptoms of dementia in nursing home residents. Nurs Older People 26, 13-36.

[16] Graneheim UH, Hörnsten A, Isaksson U (2012) Female caregivers' perceptions of reasons for violent behaviour among nursing home residents. J Psychiatr Mental Health Nurs 19, 154-161.

[17] Chou W-Y, Waszynski C, Kessler J, Chiang Y-C, Clarkson PJ (2016) Using positive images to manage resistance-tocare and combative behaviors in nursing home residents with dementia: A pilot study. Geriatr Nurs 37, 215-220.

[18] Roe J, Coulson S, Ockerby C, Hutchinson AM (2020) Staff perceptions of caring for people exhibiting behavioural and psychological symptoms of dementia in residential aged care: A cross-sectional survey. Australas J Ageing 39, 237243.

[19] Abraha I, Rimland JM, Trotta FM, Dell'Aquila G, Cruz-Jentoft A, Petrovic M, Gudmundsson A, Soiza R, O'Mahony D, Guaita A, Cherubini A (2017) Systematic review of systematic reviews of non-pharmacological interventions to treat behavioural disturbances in older patients with dementia. The SENATOR-OnTop series. BMJ Open 7, e012759.

[20] Sánchez A, Marante-Moar MP, Sarabia C, de Labra C, Lorenzo T, Maseda A, Millán-Calenti JC (2016) Multisensory stimulation as an intervention strategy for elderly patients with severe dementia: a pilot randomized controlled trial. Am J Alzheimers Dis Other Demen 31, 341-350.

[21] Feldman F, Widmer M, Connolly T, Takher A (2017) Clinical impacts of emergency department patients' exposure to photographic sky compositions. Poster presentation at: Fraser Health 4th Annual Patient Experience Conference, Surrey, BC.

[22] Scales K, Zimmerman S, Miller SJ (2018) Evidence-based nonpharmacological practices to address behavioral and psychological symptoms of dementia. Gerontologist 58, S88-102.

[23] Unity technologies. https://unity.com. Accessed August 13, 2021

[24] Gilbert SB (2009) Psychiatric crash cart: treatment strategies for the emergency department. Adv Emerg Nurs J 31, 298-308. 